\title{
Observed characteristics of lightning occurred in Lhasa city, Tibet plateau region of China
}

\author{
D.Wang ${ }^{1}$, N.Takagi ${ }^{1}$, T.Watanabe ${ }^{1}$, Y. Tie ${ }^{2}$ and X.Qie ${ }^{2}$, Y. Zhang $^{3}$ \\ ${ }^{1}$ Gifu University, Yanagito 1-1, Gifu, Japan \\ ${ }^{2}$ Cold and Arid Regions Environmental and Engineering Research Institute, Lanzhou, China \\ ${ }^{3}$ Chinese Academy of Meteorological Sciences, Beijing, China
}

\begin{abstract}
We have performed a lightning observation campaign in Lhasa city, Tibet plateau region of China. It was found that the thunderstorms in Lhasa city exhibit positive dominant electric fields at the ground and tend to produce smaller ratio of cloud-to-ground (CG) discharges. Among the CG discharges recorded, nearly $90 \%$ of them are negative ones. Compared to those occurred in low land areas, these negative CG discharges exhibit similar characteristics in terms of the number in a flash and the interstroke interval, but larger $10-$ to- $90 \%$ fast-transition rise times for both the first and subsequent strokes.
\end{abstract}

Key words: lightning discharge, return stroke, leader

\section{Introduction}

Lhasa, the capital city of Tibet Autonomous Region of China, is situated in the south central part of the plateau region $\left(\mathrm{N} 29^{\circ} 39^{\prime}, \mathrm{E} 91^{\circ} 09^{\prime}\right)$, on the North bank of the Lhasa River, and in a mountain-fringed valley. At an elevation of $3,658 \mathrm{~m}$, the city, nicknamed Sunlight City, is known as the highest city in the world. Since most of the rainfall in Lhasa occurs in nighttime, Lhasa is also known as night-rain city. Although Lhasa is fairly far from the tropical region, its yearly thunderstorm days could reach as high as 90 and mostly occur in July, August and September. Such particular thunderstorm characteristics have motivated authors to carry out a systematic lightning observation campaign there from July 14th to August 10th of 2005. Based on the data observed, we have performed a statistical study on the characteristics of lightning occurred in Lhasa city. This paper is to report part of our results.

\section{Observation}

Totally, we set up seven observation sites as shown in Fig. 1 . The sensors we employed are capacitive antenna (both slow and fast antenna) for measuring the electric field changes of lightning discharges

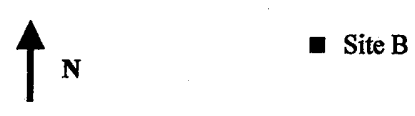

Site F

- Site E

- Site A

a Site D

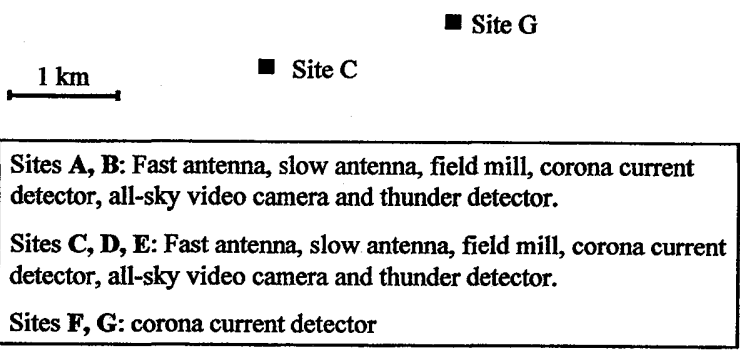

Fig. 1: Observation site map and sensor list. 
at a frequency bandwidth from several $\mathrm{Hz}$ to nearly $5 \mathrm{MHz}$, field mills and corona current detectors for measuring the electric field of thunderstorms at the ground, all-sky cameras for viewing cloud and photographing lightning discharges channels, and microphones for detecting thunders. For the present study only the data of fast antennas, slow antennas and field mills are used. The outputs from the fast antenna were recorded at a sampling rate of $10 \mathrm{MHz}$ with a digital oscilloscope operating at a trigger-waiting mode. The outputs from the slow antenna are recorded with two means: one is the same as the fast antenna and another is by a data recorder operating continuously at a sampling rate of $1 \mathrm{MHz}$. The outputs from field mills are recorded continuously at a sampling rate of $100 \mathrm{~Hz}$. All the recorders at sites $\mathrm{A}, \mathrm{B}, \mathrm{C}, \mathrm{D}$, and $\mathrm{E}$ are synchronized by GPS.

\section{Electrical characteristics of thunderstorms}

Totally, we have obtained data from 12 thunderstorms. All the storms, for which we recorded their electric field, exhibited a dominant positive electric field (according to "atmospheric electricity" sign convention) at the ground when the storms are near to our sites. As an example, Figure 2 presents the electric field of the storm occurred on July 26, 2005 at site $\mathrm{B}, \mathrm{C}$ and $\mathrm{E}$. As seen in this figure, the electric field is positive from the very beginning of the storm
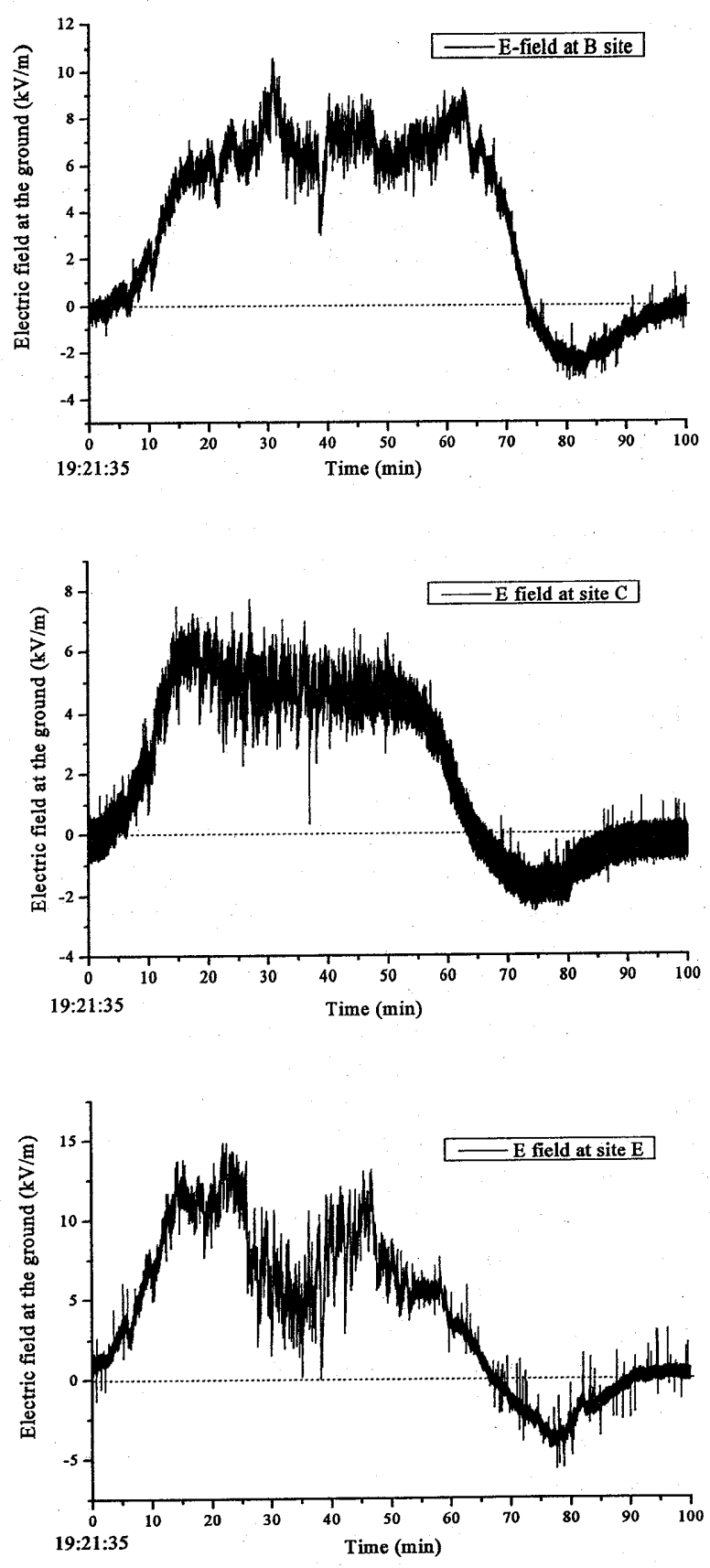

Fig. 2: The evolution of surface electric field recorded at site $\mathrm{B}, \mathrm{C}$ and $\mathrm{E}$ for the thunderstorm occurred on July 26, 2005. The sign is based on "atmospheric electricity" convention. 

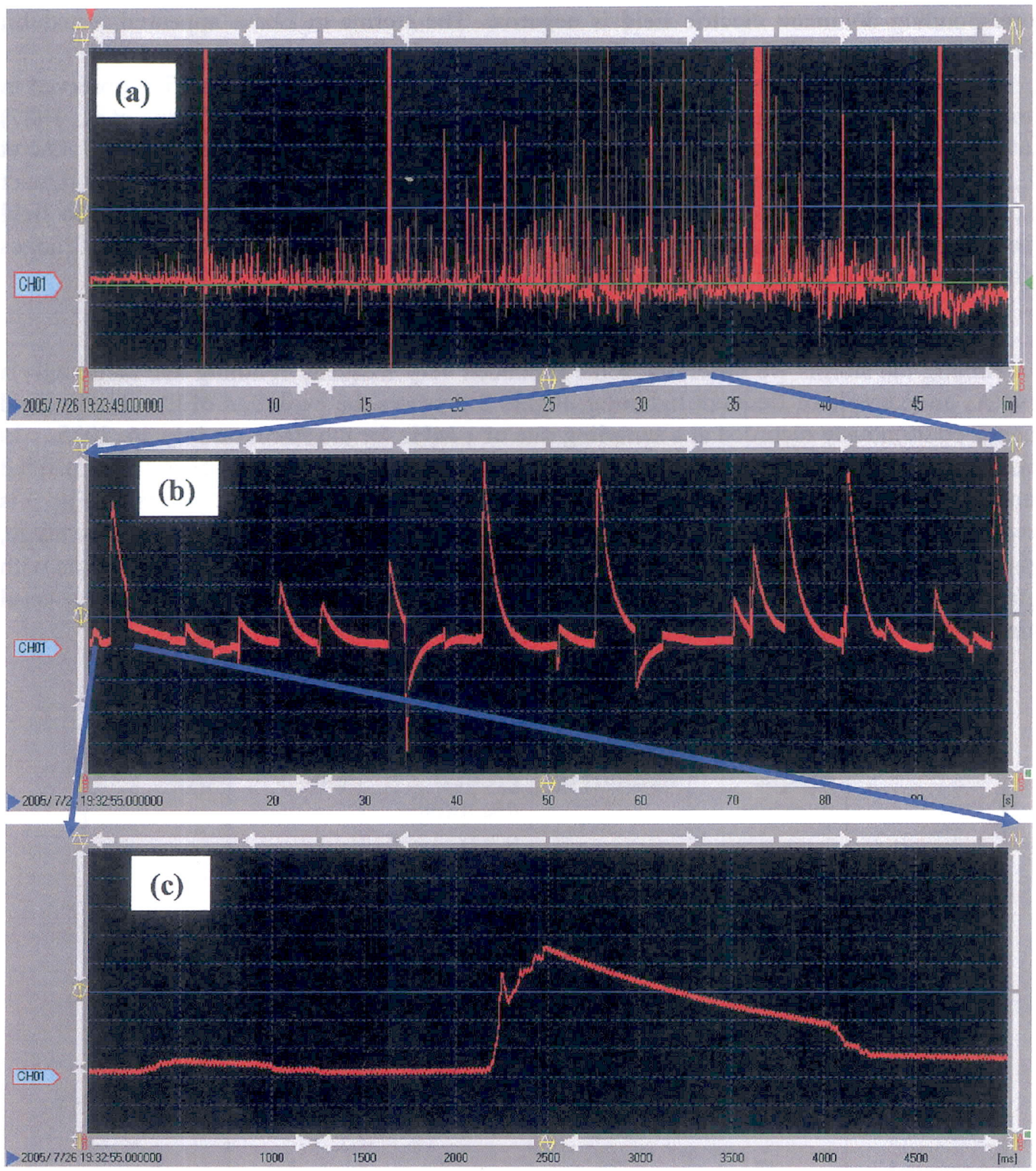

Fig. 3: The evolution of the electric field change recorded at site $\mathrm{C}$ for the thunderstorm occurred on July 26, 2005. The polarity is reversed to that of Fig. 2. (b) is the expanded version for a small portion of (a). (c) is the expanded version for a lightning flash in (b).

and lasted for nearly one hour. At the ending stage of the storm, the electric field became negative. However, the negative electric field exhibited much smaller amplitude and shorter duration than the positive electric field. Apparently, the dominant electric field is positive. It is generally known that for typical summer storms occurred in areas of low altitude, the 
corresponding dominant electric field is negative. The storms in Lhasa appeared to exhibit very different electrical characteristics in comparison to those typical summer storms.

The dominant positive electric field phenomenon as shown in Fig. 2 was first observed in Pingliang area of Gansu, a verging area of Tibet plateau about 20 years ago (Wang et al., 1987). Later, it has been observed in other areas of Gansu (Liu et al., 1989; Wang et. al., 1990; Qie et al., 2002), in Qinghai (Qie et al., 2005a), same verging areas of Tibet plateau, in Naqu (Qie et al., 2005b), central area of Tibet plateau. It appears that the dominant positive electric field phenomenon is a common feature over wide area of Qinhai-Tibet plateau, which itself ranges 1,200 kilometers from east to west and 900 kilometers north to south.

\section{Lightning activity}

Among the storms we observed, some produced very frequent lightning and some only a few. As an example of frequent lightning, Figure 3 presents the evolution of the electric field change continuously recorded at a sampling rate of $1 \mathrm{MHz}$ for the storm on July 26, 2005. In this figure, (b) is the expanded version for a small portion of (a), and (c) is the expanded version for a lightning flash in (b). The polarity of the electric field change shown in Fig. 3 is reversed to that of Fig. 2. Since each of the pulse in Fig. 3 indicates one lightning discharge, this storm exhibits a lightning frequency of $20 \mathrm{fl} / \mathrm{min}$ during the active period. For storms with fewer lightning, according to our experience, the whole lightning activity lasts only several minutes and the total lightning discharge number could be as small as 1 .

Table 1 statistical characterization of various types of discharges on different dates.

\begin{tabular}{|l|c|c|c|c|c|}
\hline Date & $\begin{array}{l}\text { Discharge } \\
\text { sample } \\
\text { number }\end{array}$ & $\begin{array}{l}\text { Cloud } \\
\text { discharges }\end{array}$ & $\begin{array}{l}\text { Cloud-to- } \\
\text { ground } \\
\text { discharges } \\
\text { (CG) }\end{array}$ & $\begin{array}{l}\text { Positive } \\
\text { CG }\end{array}$ & $\begin{array}{l}\text { Negative } \\
\text { CG }\end{array}$ \\
\hline July 19 & 96 & 94 & 2 & 0 & 2 \\
\hline July 24 & 34 & 34 & 0 & 0 & 0 \\
\hline July 25 & 41 & 40 & 1 & 1 & 0 \\
\hline July 26 & 39 & 39 & 0 & 0 & 0 \\
\hline August 1 & 5 & 5 & 0 & 0 & 0 \\
\hline August 2 & 18 & 11 & 7 & 2 & 5 \\
\hline August 4 & 43 & 36 & 7 & 1 & 6 \\
\hline August 5 & 4 & 4 & 0 & 0 & 0 \\
\hline August 6 & 91 & 83 & 8 & 0 & 8 \\
\hline August 7 & 16 & 16 & 0 & 0 & 0 \\
\hline August 8 & 7 & 7 & 0 & 0 & 0 \\
\hline August 10 & 15 & 12 & 3 & 0 & 3 \\
\hline Total & 409 & 381 & 28 & 4 & 24 \\
\hline
\end{tabular}




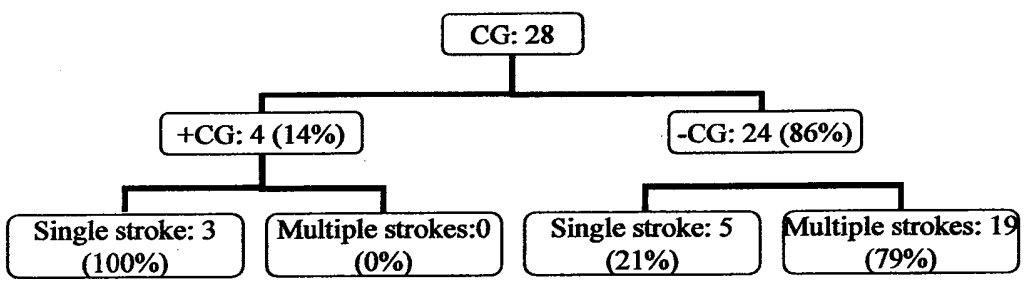

Fig. 4: Basic statistical characterization of cloud-to-ground discharges in Lhasa city.

\section{Characteristics of return strokes}

We have performed a statistical study with the data recorded during the whole observation period by digital oscilloscopes which are operated at triggering mode (not continuously). The statistical results are shown in Tables 1 and Figures 4, 5, 6, 9, 10 and 11. As seen in table 1, storms at different dates exhibit quite different characteristics with some storms tending to produce only cloud discharges and some storms producing high ratio of cloud-to-ground (CG) discharges. Although the dominant electric field is positive, the positive CG discharges are much less than the negative ones. We speculated that a favorite condition for triggering a CG discharge may be the presence of the opposite polarity of pocket charge beneath a main charge region. In Lhasa thunderstorms, a negative pocket charge may not exist just beneath the main positive charge which produced the dominant positive electric fields. This may account for the small number of the positive CG discharges. As a whole, the discharge sample size is 409 . Among the 409 lightning discharges, 28 are cloud-to-ground discharges and the remaining 381 were cloud discharges. The resultant occurrence percentage of the cloud-to-ground discharges was $7 \%$.

Among the 28 cloud-to-ground discharges, 24 were negative and the remaining 4 were positive. The percentage of the positive lightning was about $14 \%$. For negative $C G$, the histogram of the number of strokes in flash is shown in Fig. 5. As seen this figure, most of the negative CG contained multiple return strokes. As a whole, the geometric mean (GM) number is 3.4, similar to those reported for low land area negative lightning. Figure 6 presents the histogram of the time interval between successive return strokes in a flash. As a whole, the GM mean interval is $42.2 \mathrm{~ms}$, which is also similar to those observed in low land areas for negative lightning. All of the positive CG observed only contained a single stroke.

Figures 7 and 8 present the electric field change waveforms of example negative CG and positive CG. All such waveforms are similar to those observed in low land areas.

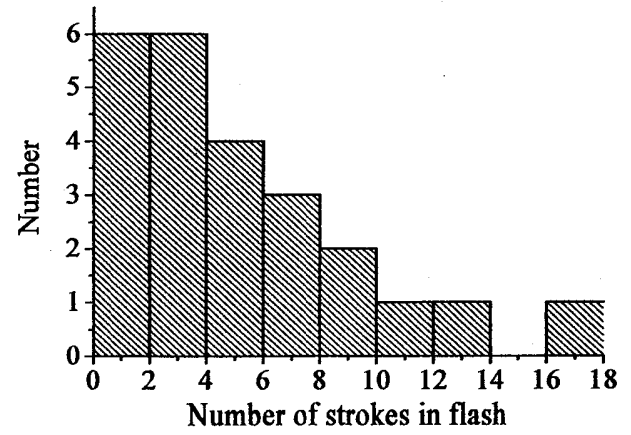

Fig. 5: Histograms of number of strokes in 24 negative CG flashes in Lhasa, Tibet of China.

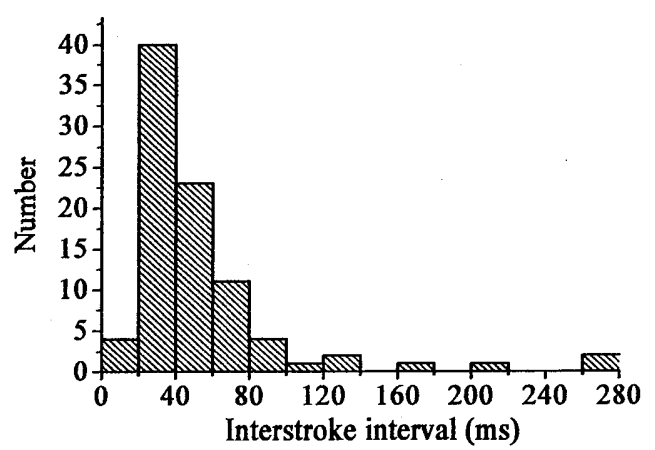

Fig. 6: Histogram of interstroke interval for 18 negative CG in Lhasa, Tibet of China. 


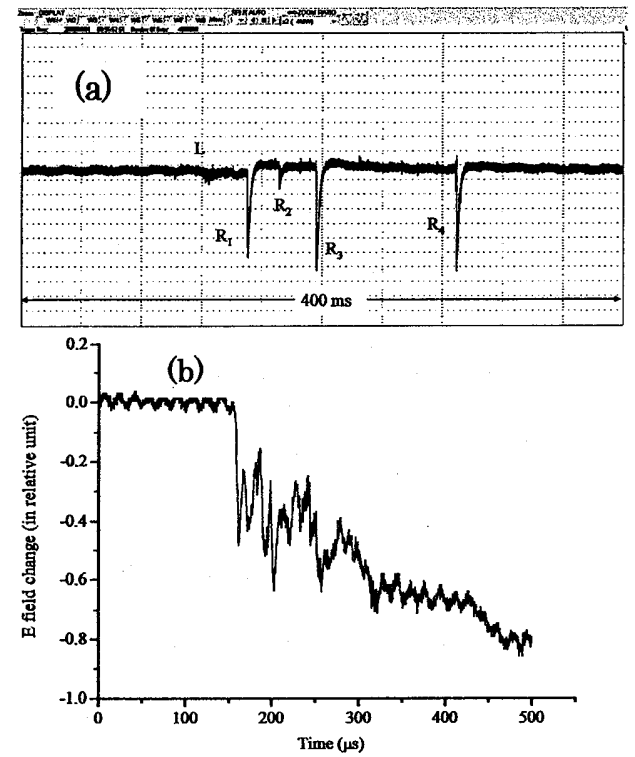

Fig. 7: Electric field change waveforms of an example negative CG. (a) is its whole waveform containing 4 return strokes and (b) is the expansion of the first stroke in (a).

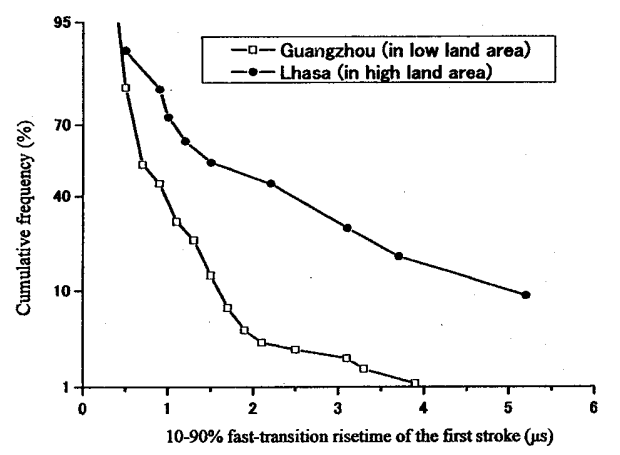

Fig. 9: The cumulative frequency of the 10 -to-90 \% fast-transition rise time of negative first strokes.

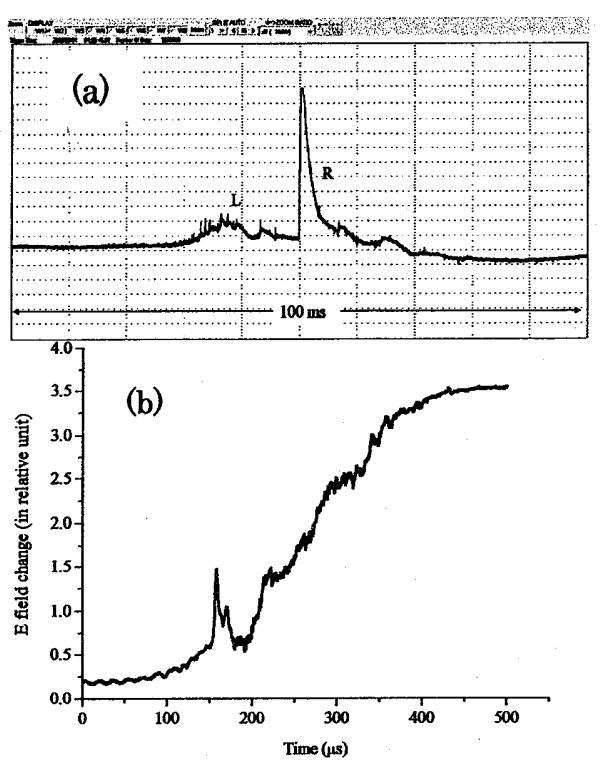

Fig. 8: Electric field change waveforms of an example positive CG. (a) is its whole waveform and (b) is the expansion of the return stroke.

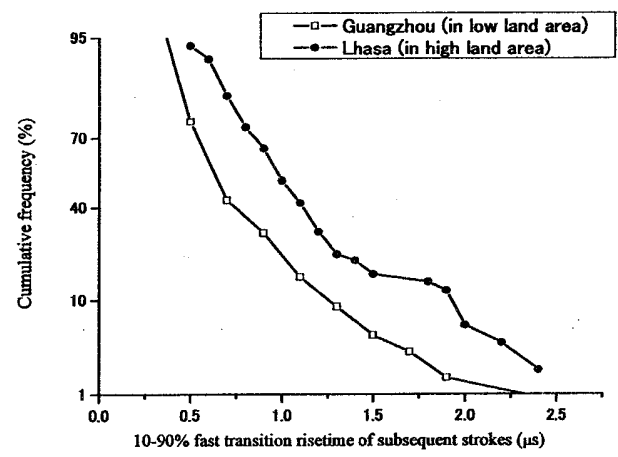

Fig. 10: The cumulative frequency of the $10-90 \%$ fast-transition rise time of subsequent strokes.

We have performed a statistical study on the $10-90 \%$ rise times of the return strokes. Figures 9 and 10 show the cumulative frequencies of the 10-to-90\% fast-transition rise time of the negative first strokes and subsequent strokes. As a comparison, the results we obtained for summer storms occurred in Guangzhou of China in 1998, an area of low altitudes are included in these two figures. Apparently, the negative strokes in Lhasa tend to have longer fast-transition rise time than those occurred in typical summer storms of low altitudes. The $50 \%$ values of 10 -to- $90 \%$ fast-transition rise negative first strokes and subsequent strokes are $1.8 \mu \mathrm{s}$ and $1.0 \mu \mathrm{s}$, respectively.

Figure 11 presents the cumulative frequency of the 10 -to- $90 \%$ fast-transition rise time of 


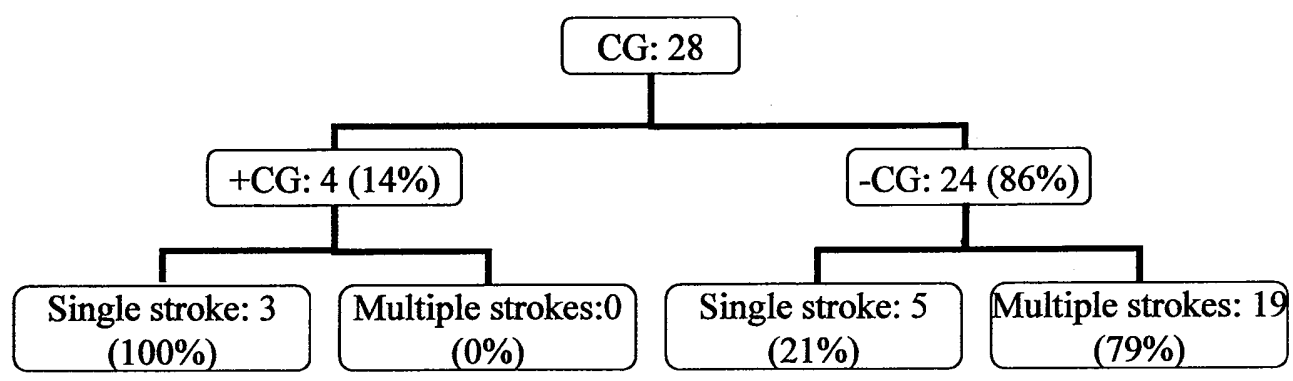

Fig. 4: Basic statistical characterization of cloud-to-ground discharges in Lhasa city.

\section{Characteristics of return strokes}

We have performed a statistical study with the data recorded during the whole observation period by digital oscilloscopes which are operated at triggering mode (not continuously). The statistical results are shown in Tables 1 and Figures 4, 5, 6, 9, 10 and 11. As seen in table 1, storms at different dates exhibit quite different characteristics with some storms tending to produce only cloud discharges and some storms producing high ratio of cloud-to-ground (CG) discharges. Although the dominant electric field is positive, the positive CG discharges are much less than the negative ones. We speculated that a favorite condition for triggering a CG discharge may be the presence of the opposite polarity of pocket charge beneath a main charge region. In Lhasa thunderstorms, a negative pocket charge may not exist just beneath the main positive charge which produced the dominant positive electric fields. This may account for the small number of the positive CG discharges. As a whole, the discharge sample size is 409 . Among the 409 lightning discharges, 28 are cloud-to-ground discharges and the remaining 381 were cloud discharges. The resultant occurrence percentage of the cloud-to-ground discharges was $7 \%$.

Among the 28 cloud-to-ground discharges, 24 were negative and the remaining 4 were positive. The percentage of the positive lightning was about $14 \%$. For negative $C G$, the histogram of the number of strokes in flash is shown in Fig. 5. As seen this figure, most of the negative CG contained multiple return strokes. As a whole, the geometric mean (GM) number is 3.4, similar to those reported for low land area negative lightning. Figure 6 presents the histogram of the time interval between successive return strokes in a flash. As a whole, the GM mean interval is $42.2 \mathrm{~ms}$, which is also similar to those observed in low land areas for negative lightning. All of the positive CG observed only contained a single stroke.

Figures 7 and 8 present the electric field change waveforms of example negative CG and positive CG. All such waveforms are similar to those observed in low land areas.

We have performed a statistical study on the $10-90 \%$ rise times of the return strokes. Figures 9 and 10 show the cumulative frequencies of the 10-to-90\% fast-transition rise time of the negative first strokes and subsequent strokes. As a comparison, the results we obtained for summer storms occurred in Guangzhou of China in 1998, an area of low altitudes are included in these two figures. Apparently, the negative strokes in Lhasa tend to have longer fast-transition rise time than those occurred in typical summer storms of low altitudes. The 

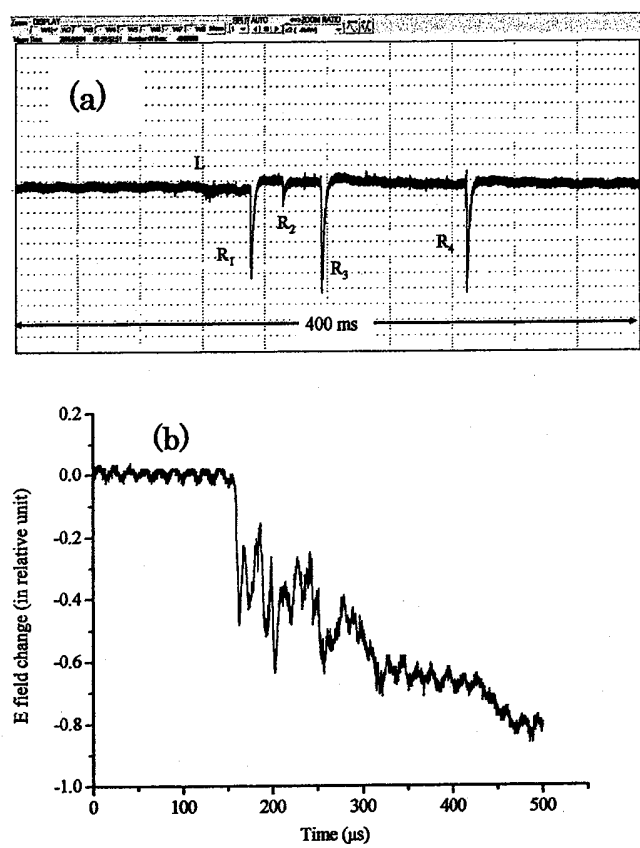

Fig. 7: Electric field change waveforms of an example negative CG. (a) is its whole waveform containing 4 return strokes and (b) is the expansion of the first stroke in (a).

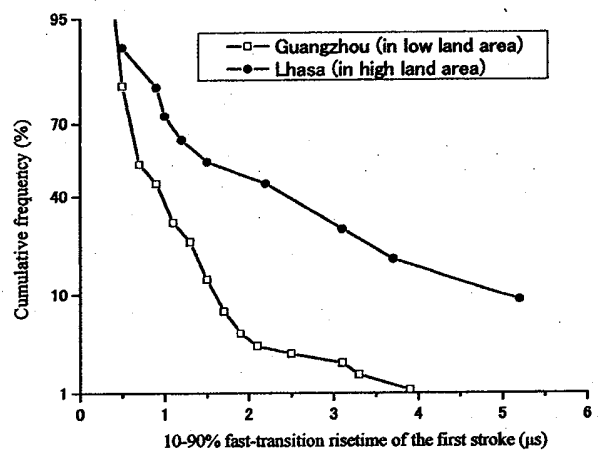

Fig. 9: The cumulative frequency of the 10-to-90\% fast-transition rise time of negative first strokes.
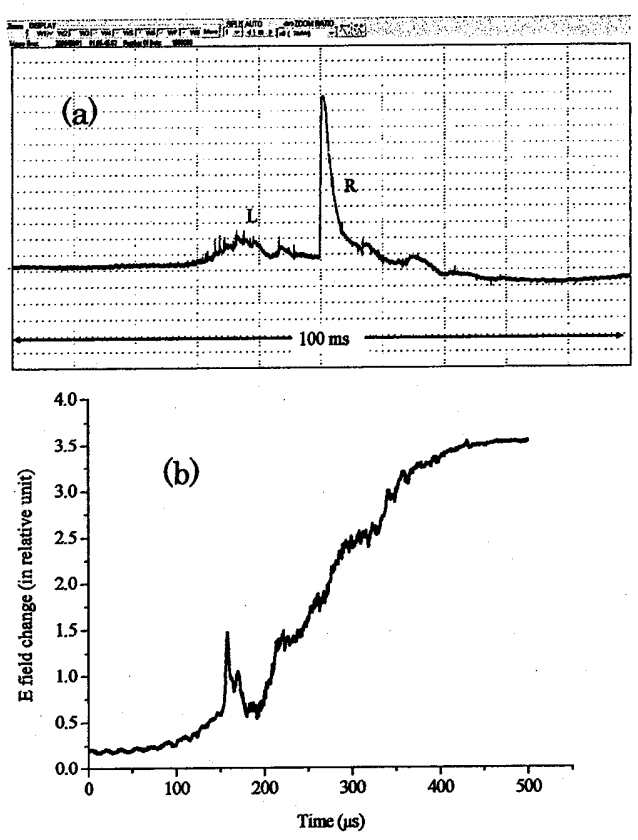

Fig. 8: Electric field change waveforms of an example positive CG. (a) is its whole waveform and (b) is the expansion of the return stroke.

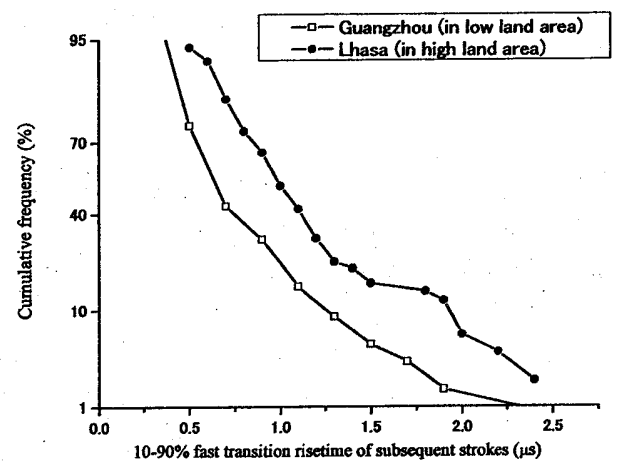

Fig. 10: The cumulative frequency of the $10-90 \%$ fast-transition rise time of subsequent strokes.

$50 \%$ values of 10 -to- $90 \%$ fast-transition rise negative first strokes and subsequent strokes are $1.8 \mu \mathrm{s}$ and $1.0 \mu \mathrm{s}$, respectively.

Figure 11 presents the cumulative frequency of the 10 -to-90 \% fast-transition rise time of 
the positive strokes. As a comparison, the result we obtained for Japanese winter storms is included in the figure. It appears that the positive strokes in Lhasa tend to have longer fast-transition rise time than those occurred in Japanese winter storms. The $50 \%$ values of 10-to-90\% fast-transition rise time of Lhasa positive strokes is $1.9 \mu \mathrm{s}$.

\section{Concluding remarks}

This paper has reported some preliminary results obtained in a campaign designed to study the detailed characteristics of lightning occurred in Lhasa city, Tibet plateau region of China.

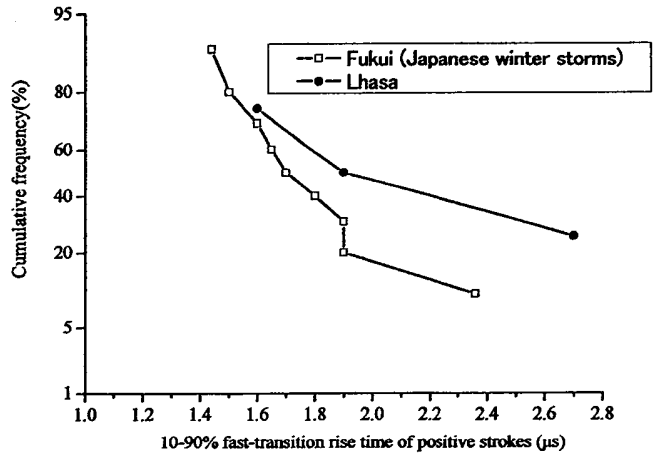

Fig. 11: The cumulative frequency of the 10-to-90\% fast-transition rise time of positive strokes.

It was found that the thunderstorms in

Lhasa can be characterized with positive dominant electric fields on the ground and producing smaller ratio of cloud-to-ground discharges. The $50 \%$ values of the $10-$ to- $90 \%$ fast-transition rise times for the first and subsequent strokes of the negative CG of Lhasa are $1.8 \mu$ s and 1.0 $\mu \mathrm{s}$, respectively. The corresponding value for the positive strokes is $1.9 \mu \mathrm{s}$.

\section{Acknowledgement}

This work was supported by Grand-in-Aid for Scientific Research of the Ministry of Education, Science, Sports and Culture, Japan. H. Horibe and K.Minamitani made great contribution in performing the observation experiments. During our observation campaign, Lhasa Meteorological Bureau and Chengdou University of Information Technology have provided a lot of convenience. We appreciate C. Guo, Z. Xiao, D. Zhou, D. Ying, Y. Ma, Z. Qiang, B. Ci, D. Wei for their individual help.

\section{References}

Liu, X, Z. Ye, X. Shao, C. Wang, M. Yan, and C. Guo, Intracloud lightning discharge in the lower part of thundercloud, Acta Meteorol. Sin., 3, 212-219, 1989.

Qie, X., Y. Yu, D. Wang, H. Wang, R. Chu, Characteristics of cloud-to-ground lightning in Chinese Inland Plateau, J. Meteorol. Soc. Jpn.80, 745-754, 2002.

Qie, X., X. Kong, G. Zhang, T. Zhang, T. Yuan, Y. Zhou, Y. Zhang, H. Wang, A. Sun, The possible charge structure of thunderstorm and lightning discharges in north-eastern verge of Qinhai-Tibetan Plateau, Atmospheric Research, 76, 231-246, 2005a.

Qie, X., T. Zhang, C. Chen, G. Zhang, T. Zhang, and W. Wei, The lower positive charge center and its effect on lightning discharges on Tibetan Plateau, Geophy. Res. Lett., 32, L05814, doi:10.1029/2004GL022162, 2005b.

Wang, C., Q. Chen, and X. Liu, The electric field produced by the lower positive charge center of thunderstorm, Plateau Meteorol. 6, 65-74, 1987 (in Chinese).

Wang, D, X. Liu, and C. Wang, A preliminary analysis of the characteristics of ground discharges in thunderstorms near Zhongchuan, Gansu Province, Plateau Meteorol. 9, 405-410, 1990 (in Chinese).

(Received June 20, 2006; revised September 15, 2006; accepted October 31, 2006) 